\title{
Characteristics of Histidine Uptake by Human Placental Microvillous Membrane Vesicles
}

\author{
PETER I. KARL, HELEN TKACZEVSKI, AND STANLEY E. FISHER \\ Departments of Pediatrics and Research, North Shore University Hospital, and Department of Pediatrics, Cornell \\ University Medical College, Manhasset, New York 11030
}

\begin{abstract}
L-histidine is an essential amino acid. Its fetal-to-maternal blood concentration ratio is high, suggesting active placental transport. In this study, human placental microvillous membrane vesicles were used to characterize $L$-histidine transport, heretofore not evaluated in human tissue. L-Histidine uptake by microvillous membrane vesicles was stimulated by an inward sodium gradient, leading to an "overshoot," followed by apparent equilibration. Linear uptake at $22^{\circ} \mathrm{C}$ was limited to the 1 st min. The initial sodium-dependent uptake rate was proportional to the sodium concentration in the medium. The sodium-dependent uptake was markedly diminished or lost when potassium, cesium, or choline was substituted for sodium but not lithium. Replacement of chloride with sulfate or gluconate had little effect. Sodium-stimulated Lhistidine uptake was further stimulated by an outward potassium gradient (inside-negative) in the presence of valinomycin. Sodium-dependent uptake kinetic constants for L-histidine were: $\mathrm{Km}=0.44 \pm 0.18 \mathrm{mM}$ : $V_{\max }=536$ $\pm 94 \mathrm{nmol} / \mathrm{mg} / 30 \mathrm{~s}$ (mean $\pm \mathrm{SD}$ ). 2-(methylamino)isobutyric acid did not inhibite L-histidine uptake. Conversely, L-histidine noncompetitively inhibited sodium-dependent uptake of 2-(methylamino)isobutyric acid and $\mathrm{L}$ cysteine. L-glutamine competitively inhibited sodium-dependent L-histidine uptake. L-histidine uptake was stimulated by preloading the vesicles with either L-histidine or L-glutamine (transstimulation). L-histidine uptake was not sensitive to $N$-ethylmaleimide treatment but was strongly inhibited by low $\mathrm{pH}$. These findings suggest that L-histidine is transported in the human placenta by a specific sodium-dependent system similar to the " $N$ " system described in rodent hepatocytes. Furthermore, the ready availability of placental tissue may make it a useful resource for studies of human epithelial transport biology. (Pediatr Res 25:19-26, 1989)
\end{abstract}

\section{Abbreviations}

MeAIB, 2-(methylamino)isobutyric acid

MMV, microvillous membrane vesicles

HTM solution, $10 \mathrm{mM}$ HEPES-Tris buffer, $\mathrm{pH} 7.4$, with $300 \mathrm{mM}$ mannitol

The transport of amino acids across the human placenta is crucial for normal growth and development of the fetus. The

Received April 18, 1988; accepted August 31, 1988.

Correspondence Dr. Peter I. Karl, Boas-Marks Biomedical Science Research Center, North Shore University Hospital, 350 Community Drive, Manhasset, NY 11030.

Supported in part by PHS Grants HD17375 and AA07284. Dr. Fisher is the recipient of Research Scientist Development Award AA00074. placenta transfers amino acids to the fetus (1), with uptake occurring at the microvillous membrane. Isolation of human placental MMV was originally described by Smith et al. (2). MMV preparations permit studies of membrane-associated transport without certain confounding variables, such as intracellular metabolism, and are restricted to a specific region of the cell surface. Basic measurements have been made for the uptake of some amino acids by human placental MMV (3-8), but no analyses have been performed on the essential amino acid, histidine. We report here several parameters of human placental MMV uptake of L-histidine, an important amino acid for which transport characteristics have been described only in nonplacental animal tissue.

L-Histidine is an essential amino acid in humans (9), being of particular importance during periods of rapid growth (10). It is a precursor in the process of folate-dependent DNA synthesis (9), and its potential importance for fetal development is reflected in the steep fetal-to-maternal concentration ratio in blood (1).

L-histidine transport is thought to occur by a relatively specific, sodium-dependent, membrane-associated mechanism or "system." However, the "N" system for L-histidine has only been demonstrated in nonplacental animal tissue, particularly rat hepatocytes (11). We have used several parameters characteristic of the rodent hepatocyte system $\mathrm{N}$ to examine L-histidine uptake by human placental MMV.

\section{MATERIALS AND METHODS}

Materials. $\left[{ }^{3} \mathrm{H}\right]$ histidine $(54.4 \mathrm{Ci} / \mathrm{mmol}),\left[{ }^{14} \mathrm{C}\right]$ histidine $(280$ $\mathrm{mCi} / \mathrm{mmol}),\left[{ }^{14} \mathrm{C}\right]$ glutamine $(280 \mathrm{mCi} / \mathrm{mmol}),\left[{ }^{14} \mathrm{C}\right]$ cystine $(306$ $\mathrm{mCi} / \mathrm{mmol}), \quad\left[{ }^{35} \mathrm{~S}\right]$ cystine $(978 \mathrm{Ci} / \mathrm{mmol}), \quad\left[{ }^{14} \mathrm{C}\right] 2-($ methylamino)isobutyric acid $(48.4 \mathrm{mCi} / \mathrm{mmol})$, and $\left[{ }^{14} \mathrm{C}\right]$ phenylalanine $(512 \mathrm{mCi} / \mathrm{mmol})$ were obtained from New England Nuclear (Boston, MA), and $\left[{ }^{3} \mathrm{H}\right]$ cystine $(1.4 \mathrm{Ci} / \mathrm{mmol})$ from Amersham (Arlington Heights, IL). Unlabeled amino acids, HEPES, Tris base, mannitol, sodium chloride, choline chloride, lithium chloride, sodium sulfate and sodium gluconate were from Sigma Chemical Co. (St. Louis, MO). In order to obtain radioactive Lcysteine from L-cystine, a final concentration of $5 \mathrm{mM}$ dithiothreitol was included in the incubation medium (11).

$M M V$ preparation. The placentas were obtained immediately after either cesarean or vaginal delivery. MMV were prepared by a modification (12) of the method of Smith et al. (2). Briefly, the placentas from normal term delivery (37-40 wk gestation) were placed in ice-cold saline and processed immediately. Both the maternal decidual and fetal membranes were removed, and blood vessels were carefully dissected away. A total of 100-150 $\mathrm{g}$ of tissue was washed with HTM solution. Washed tissue fragments were placed in $300 \mathrm{ml}$ of HTM solution and stirred with a magnetic stirrer $(70 \mathrm{rpm})$ for $30 \mathrm{~min}$ at $4^{\circ} \mathrm{C}$. The suspension was filtered through six layers of cheesecloth, and the filtrate was centrifuged for $10 \mathrm{~min}$ at $10,000 \times \mathrm{g}$ to remove debris. The supernatants were combined, mixed, and centrifuged 
for $30 \mathrm{~min}$ at $105,000 \times \mathrm{g}$. The pellets were combined and resuspended in HTM solution using a loose-fitting Dounce homogenizer. Concentrated $\mathrm{MgCl}_{2}$ solution (1 M) was added to a final concentration of $10 \mathrm{mM}$. The preparation was mixed thoroughly, placed on ice for $10 \mathrm{~min}$ and centrifuged at $3000 \times$ $\mathrm{g}$ for $15 \mathrm{~min}$ to remove non-MVM. The supernatant was centrifuged for $30 \mathrm{~min}$ at $105,000 \times \mathrm{g}$. $\mathrm{MgCl}$ was removed by washing the pellet twice and resuspending in HTM solution with a loosefitting Dounce homogenizer. The suspension was centrifuged for $30 \mathrm{~min}$ at $105,000 \times \mathrm{g}$. The final pellet was suspended in HTM solution to a final protein concentration of $5-7 \mathrm{mg} / \mathrm{ml}$ after passing it 20 times through a 25 gauge needle. Using this method, $100 \mathrm{-g}$ tissue fragments resulted in about $30 \mathrm{mg}$ of MMV protein. The vesicle preparation was stored at $2^{\circ} \mathrm{C}$ for transport studies and at $-80^{\circ} \mathrm{C}$ for enzyme analyses. Our preliminary studies showed that freezing at $-80^{\circ} \mathrm{C}$ greatly reduces sodium-stimulated histidine transport by MMV. However, transport activity is unaffected for at least 4 days when stored at $2^{\circ} \mathrm{C}$. All transport studies used the vesicles within 3 days of preparation.

Uptake experiments. Uptake was determined by adding the MMV preparation to the incubation medium containing radiolabeled substrates and various ions (see text, tables, or figure legends for specific compositions which varied with experimental purpose). Usually, the MMV preparation was added to the incubation medium in a ratio of $1: 4$ (vol:vol) except for the $\mathrm{pH}$ study, which was 1:9) at $22^{\circ} \mathrm{C}$. After incubation, $50 \mu 1$ of the mixture was rapidly filtered by negative pressure through prewetted nitrocellulose filters (Millipore Continental Water Systems, Bedford, MA, or Gelman Sciences, Inc., Ann Arbor, MI: pore size $0.45 \mu \mathrm{m}$ ) and washed four times with $4 \mathrm{ml}$ of ice-cold incubation buffer. This process was completed within $10 \mathrm{~s}$. The filters were dissolved in $2 \mathrm{ml}$ Cellosolve (Fisher Scientific, Springfield, NJ) and $10 \mathrm{ml} \mathrm{Liquiscint} \mathrm{(National} \mathrm{Diagnostic,} \mathrm{Manville,}$ NJ) were added before determining radioactivity in a Packard Tricarb Scintillation Analyzer 2000CA (Hewlett Packard Co., Palo Alto, CA). Samples for each data point were evaluated at least in triplicate. Nonspecific binding of radioactivity to the filter was less than $0.02 \%$ of the total radioactivity applied to the filter. This background activity was subtracted from uptake data.

The effect of electrical potential on sodium stimulated Lhistidine uptake was determined using vesicles prepared in 100 $\mathrm{mM}$ potassium gluconate, $100 \mathrm{mM}$ mannitol, and $10 \mathrm{mM}$ HEPES-Tris buffer. These vesicle were incubated with the potassium ionophore, valinomycin $(12.5 \mu \mathrm{g} / \mathrm{mg}$ protein), for $30 \mathrm{~min}$ at $37^{\circ} \mathrm{C}$. Enhanced electrical potential was generated by diluting the vesicle into solution containing $50 \mathrm{mM}$ sodium chloride, 200 $\mathrm{mM}$ mannitol, and HEPES-Tris buffer which contained $100 \mu \mathrm{M}$ radioactive $\mathrm{L}$-histidine. Control uptake was measured in buffer containing $50 \mathrm{mM}$ sodium chloride, $100 \mathrm{mM}$ potassium gluconate, and HEPES-Tris buffer.

Enzyme assay. Alkaline phosphatase was determined by the liberation of $p$-nitrophenol from $p$-nitrophenol phosphate in 50 $\mathrm{mM}$ glycine/ $\mathrm{NaOH}$ buffer $(\mathrm{pH} 10.5)$ in the presence of $0.5 \mathrm{mM}$ $\mathrm{MgCl}_{2}$ (sigma Technical Bulletin 104). 5'-nucleotidase was assayed with AMP as the substrate in $50 \mathrm{mM}$ Tris/HCl buffer, $\mathrm{pH}$ 8.5 (Sigma Technical Bulletin 675). The liberated phosphate was determined colorimetrically by the method of Chen et al. (13). $\mathrm{Na}^{+} / \mathrm{K}^{+}$-ATPase was determined by the method of Marks and Seeds (14), wherein ATP is regenerated to avoid product inhibition. To this reaction mix, $\mathrm{NaN}_{3}$ is added to reduce activity of nonspecific phosphatases (15). The assay contained $40 \mathrm{mM}$ Tris$\mathrm{HCl}, \mathrm{pH} 4$, with $100 \mathrm{mM} \mathrm{NaCl}, 15 \mathrm{mM} \mathrm{NaN}_{3}, 20 \mathrm{mM} \mathrm{KCl}, 3$ $\mathrm{mM} \mathrm{MgCl}, 0.5 \mathrm{mM}$ EDTA, $3 \mathrm{mM}$ ATP, $1.5 \mathrm{mM}$ phospho(enol)pyruvate and $10 \mathrm{U}$ of pyruvate kinase; $\pm 1 \mathrm{mM}$ ouabain. $\mathrm{Na}^{+} / \mathrm{K}^{+}$-ATPase activity was determined as the ouabainsensitive production of phosphate from ATP at $37^{\circ} \mathrm{C}$ over a 20 min period. Protein was determined by the method of Markwell et al. (16), a modification of the original method of Lowry et al. (17). This method allows assay of protein in the presence of high lipid concentration.
Data expression. Data are represented as mean \pm SD and analyzed by the $t$ test for paired data or by ANOVA. Differences between group means were considered significant for $p<0.05$. The least squares method (Statgraphics) was used to obtain the best fitting lines for analysis of uptake kinetics.

\section{RESULTS and DISCUSSION}

Characterization of $M M V$ preparation. 5'-Nucelotidase and alkaline phosphatase, enzymes known to be present in the microvillous membrane were enriched greater than 49 - and 27 -fold, respectively, in all preparations $\left(5^{\prime}\right.$-nucleotidase: homogenate $=$ $3.3 \pm 1.4($ mean $\pm \mathrm{SD})$; vesicle preparation $=162 \pm 43 \mu \mathrm{mol}$ $\mathrm{P}_{\mathrm{i}} \cdot \mathrm{mg}^{-1} \cdot \mathrm{min}^{-1}$; alkaline phosphatase: homogenate $=0.13 \pm$ 0.04 ; vesicle preparation $=3.38 \pm 0.79 \mu$ nmol $p$-nitrophenyl. $\left.\mathrm{mg}^{-1} \cdot \mathrm{min}^{-1}\right)$. The activity of $\mathrm{Na}^{+} / \mathrm{K}^{+}$-ATPase was slightly enriched in these preparations (homogenate $=66 \pm 27$; vesicle $=$ $\left.563 \pm 118 \mathrm{nmol} \mathrm{P}_{\mathrm{i}} \cdot \mathrm{mg}^{-1} \cdot 20 \mathrm{~min}^{-1}\right)$. These data are similar to an earlier observation (18) which showed an enrichment of approximately 6 -fold of $\mathrm{Na}^{+} / \mathrm{K}^{+}$-ATPase activity in MMV preparations. As they explained, the modest increase in $\mathrm{Na}^{+} / \mathrm{K}^{+}$ATPase activity may be due to the fact that the placenta consists of structures which are mostly devoid of $\mathrm{Na}^{+} / \mathrm{K}^{+}$-ATPase. Therefore, the whole tissue homogenate is relatively low in activity, making detection difficult, and the slightest contamination during purification could result in apparent enrichment.

Transmission electron microscopy of vesicle preparations (not shown) revealed closed vesicular structures with absence of any identifiable organelles. Treatment of the MMV with $1 \%$ Triton $\mathrm{X}-100$ increased the alkaline phosphatase activity by only $6 \%$ (control $=4.63 \pm 0.01$; Triton treated $=5.17 \pm 0.02 \mu \mathrm{mol}$. $\mathrm{mg}^{-1} \cdot \min ^{-1}$ ), indicating that the vast majority of the vesicles were facing right side out (3).

The intravesicular space was measured as described by Kletzien et al. (19) using 3-O-methylglucose, a nonmetabolized hexose. Determined from six different preparations, the space was $0.38 \pm 0.05 \mu \mathrm{l} / \mathrm{mg}$ protein. Relative to the vol of the medium, the MMV vol is quite small, as incubation concentrations are approximately $1 \mathrm{mg}$ protein $/ \mathrm{ml}$ medium. Our observation is similar to that of Boyd and Lund (4) $(0.5 \mu \mathrm{l} / \mathrm{mg})$ and Asai et al. (6) $(0.587 \pm 0.124 \mu \mathrm{l} / \mathrm{mg})$, but iower than the results of Ruzycki et al. (3/12) $(3.85 \mu \mathrm{l} / \mathrm{mg})$ or Balkovetz et al. (14) $(2.7 \pm 0.7 \mu \mathrm{l} /$ $\mathrm{mg})$. An explanation for these differences is not immediately apparent.

Uptake of L-histidine was linear over a range of vesicle protein concentration: $20-100 \mu \mathrm{g} / 50 \mu \mathrm{l}$ reaction. All subsequent uptake experiments were carried out using $50-60 \mu \mathrm{g}$ of vesicle protein in $50 \mu \mathrm{l}$ incubation vol.

Effect of osmolarity and temperature on L-histidine transport. To demonstrate that the apparent uptake of radioactive amino acid represents translocation into the intravesicular space, sensitivity of L-histidine uptake to changes in the osmolarity of the uptake medium was determined. Osmolarity of the medium was changed by varying the concentration of sucrose, a relatively impermeable solute. Increasing medium osmolarity decreases intravesicular space (20). A plot of uptake versus 1 /osmolarity yielded linear line $(r=0.992)$ with $y$-intercept of $78.1 \mathrm{pmol} \cdot \mathrm{mg}$ protein $^{-1}$ which is $26.5 \%$ of uptake at the standard osmolarity of $300\left(295 \mathrm{pmol} \cdot \mathrm{mg}\right.$ protein $\left.{ }^{-1}\right)$. The radioactivity associated with the vesicles was inversely proportional to osmolarity. The results indicate that the L-histidine uptake measurements represents entry of the amino acid into a changing MMV space, rather than nonspecific binding to the membrane.

This conclusion was reinforced by studies of uptake at $4^{\circ} \mathrm{C}$. When sodium gradient-dependent $\mathrm{L}$-histidine uptake was studied at $4^{\circ} \mathrm{C}$, maximum uptake was only $27.5 \%$ of that at $22^{\circ} \mathrm{C}(303.9$ \pm 15.9 and $54.4 \pm 9.1 \mathrm{pmol} \cdot \mathrm{mg}$ protein ${ }^{-1} \cdot 30 \mathrm{~s}^{-1}$ at $22^{\circ} \mathrm{C}$ and $4^{\circ} \mathrm{C}$, respectively; $p<0.05$ ). As reported by others (3-8), all experiments characterizing L-histidine uptake were performed at $22^{\circ} \mathrm{C}$.

Time course of L-histidine and L-glutamine transport. Time- 
dependent uptake of L-histidine and L-glutamine are shown in Figure $1 A$ and $B$. Uptake of amino acids was determined in the presence of either $100 \mathrm{mM}$ sodium chloride or $100 \mathrm{mM}$ choline chloride (control) in the incubation medium. The presence of an inward $100 \mathrm{mM}$ sodium gradient stimulated the transport of both amino acids relative to $100 \mathrm{mM}$ choline chloride. Uptake was rapid at the beginning, representing an "overshoot" phenomenon which peaked at 5-10 min and gradually approached equilibrium by $2 \mathrm{~h}$, the last time point measured. Uptake in the absence of a sodium gradient was slow until it plateaued (Fig. 1). The final concentration of amino acids in the MMV was similar in the presence or absence of a sodium gradient, suggesting passive diffusion plus release of initially active transported substrate and eventual dissipation of the initial sodium gradient $(6$, $20)$. At the peak of the "overshoot," the uptake of L-histidine and L-glutamine were about three times the final equilibrium value. These results imply that the inward sodium gradient stimulates movement of L-histidine into placental membrane vesicles. Silica thin-layer chromatography (isopropanol/1 N $\mathrm{HCl} / \mathrm{H}_{2} \mathrm{O} ; 65: 15.6: 18.4$ ) showed lack of metabolism of the $\mathrm{L}-$ histidine: after $2 \mathrm{~h}$ incubation with MMV, $95-100 \%$ of the label appeared at the same $\mathrm{Rf}(0.5)$ as the L-histidine standard.

Kinetic analysis of L-histidine uptake. The time course (Fig. 2) shows that initial sodium-dependent uptake of L-histidine is linear for more than $30 \mathrm{~s}$. Therefore, concentration-dependent velocity of L-histidine uptake was determined at $30 \mathrm{~s}$. The effect of different concentrations of L-histidine on the rate of amino acid uptake, in the absence and presence of sodium, is illustrated in Figure 2. In the absence of sodium, the rate of uptake increased linearly with increasing L-histidine concentration throughout a range from $0.02-5 \mathrm{mM}$. In the presence of a sodium gradient, the relationship between L-histidine concentration and uptake was nonlinear and appeared saturable at low concentrations (approximately $0.5 \mathrm{mM}$ ). For higher L-histidine concentrations,

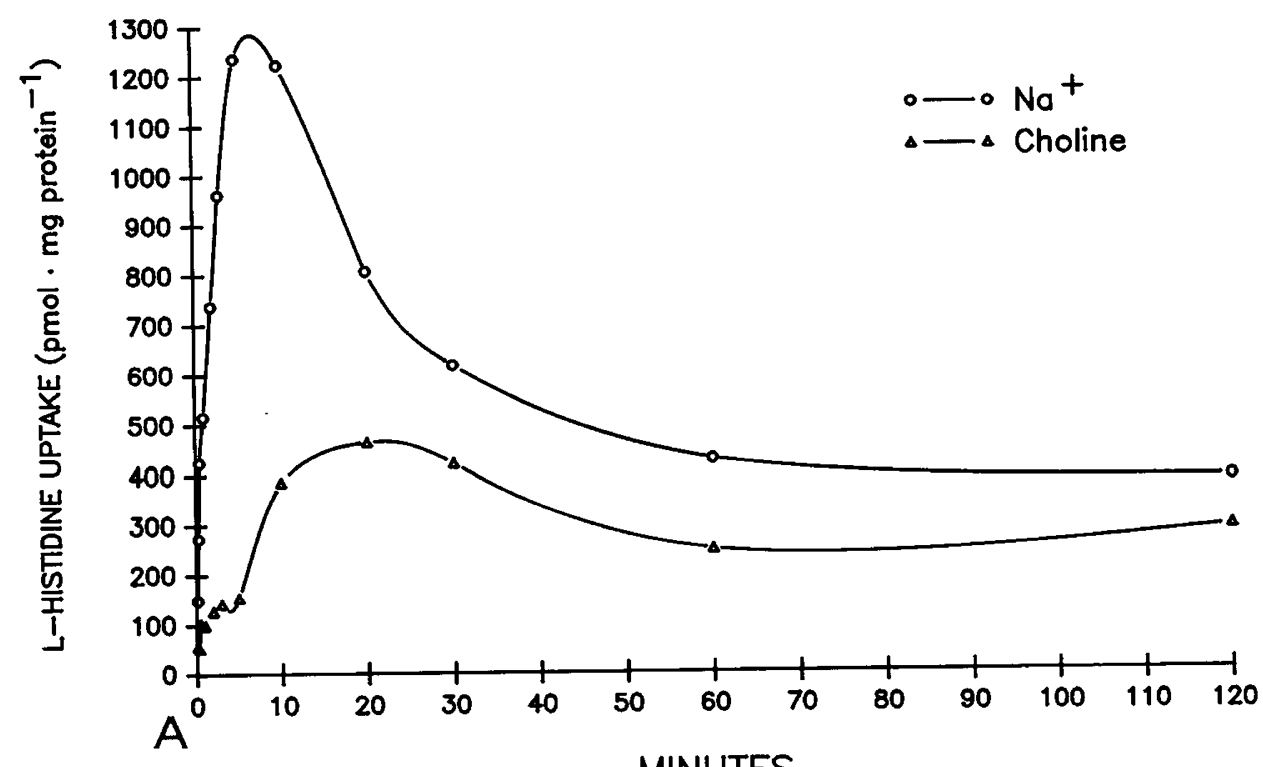

MINUTES

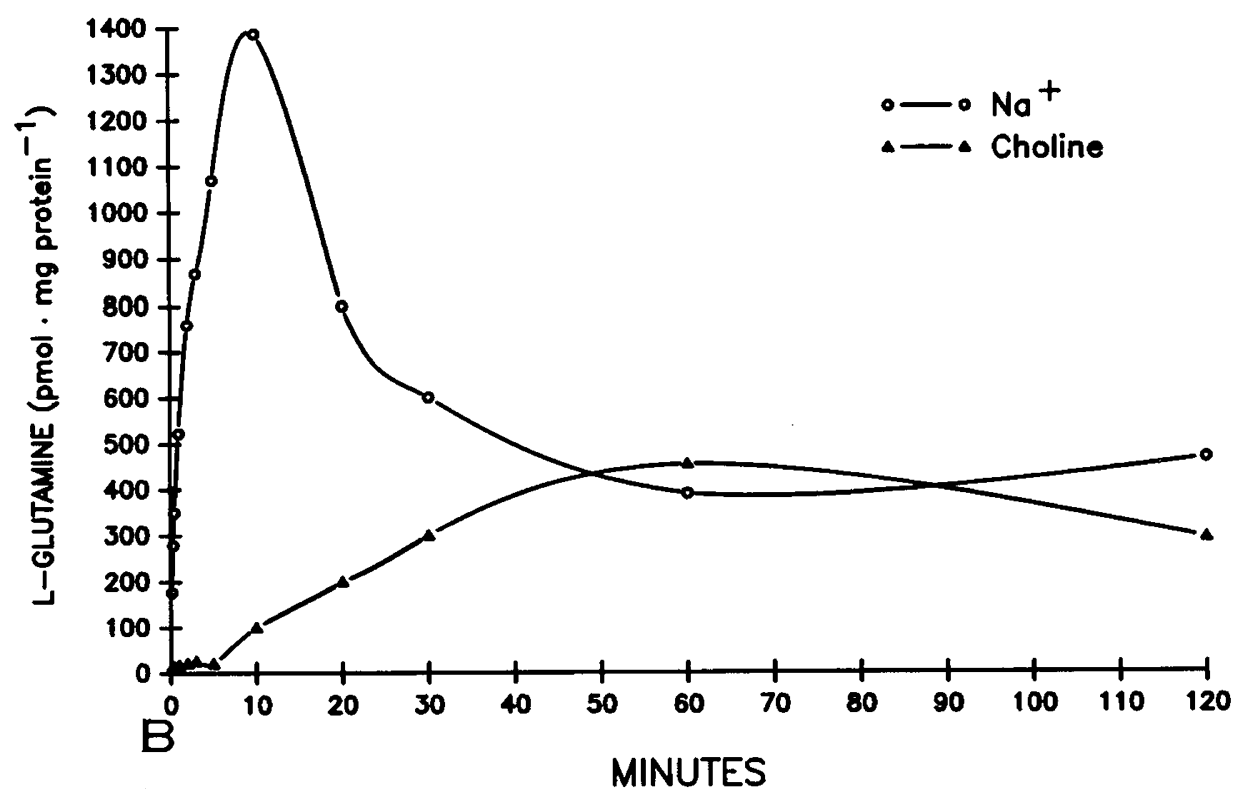

Fig. 1. Time-dependent uptake of L-histidine and L-glutamine by MMV. Incubations were carried out with $100 \mu \mathrm{M} \mathrm{L-histidine}(A)$ or L-glutamine $(B)$ at $22^{\circ} \mathrm{C}$ in the presence of sodium or choline. Uptake was terminated by rapid filtration at indicated times. Results are mean \pm SD of three to six determinations. 


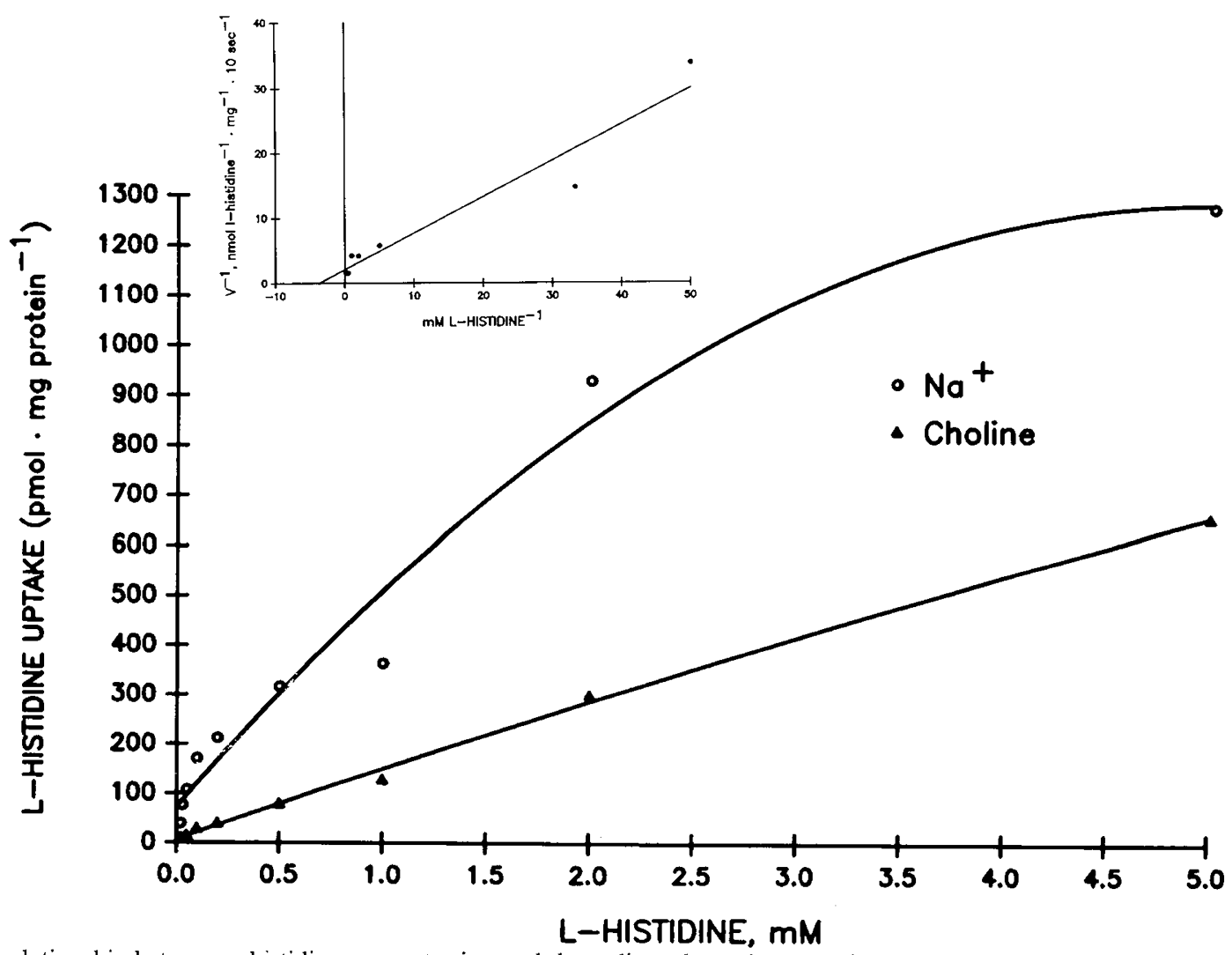

Fig. 2. The relationship between L-histidine concentration and the sodium-dependent and -independent initial rates of uptake of $\left[{ }^{3} \mathrm{H}\right] \mathrm{L}$-histidine by MMV. Incubations were for $30 \mathrm{sec}$ in $10 \mathrm{mM}$ HEPES-Tris buffer, $\mathrm{pH} 7.4$, containing either $100 \mathrm{mM} \mathrm{NaCl}$ or ChCl. Inset, double reciprocal plot of the sodium-dependent L-histidine uptake by MMV.

uptake was linearly related to amino acid concentration in a pattern of simple diffusion.

To determine sodium gradient-dependent uptake kinetics, uptake in choline-containing medium was subtracted from uptake in the presence of sodium. A Lineweaver-Burk plot of the rate of the sodium-dependent uptake as a function of L-histidine concentration shows a linear relationship (Fig. 2, inset). The results are consistent with uptake by a single transport system. The calculated uptake kinetic constants from five vesicle preparations were $\mathrm{Km}=0.44 \pm 0.18 \mathrm{mM}$ and $\mathrm{V}_{\max }=536 \pm 94 \mathrm{nmol}$. $\mathrm{mg}$ protein ${ }^{-1} \cdot 30 \mathrm{~s}^{-1}$. These results are similar to those observed for proline in placental microvillous vesicles (4).

Effect of cation and anion gradients on L-histidine transport. To determine the specificity of L-histidine uptake for sodium stimulation, sodium was replaced with other cations (Table 1 and Fig. 3). L-histidine uptake was virtually abolished when the uptake medium contained only HTM solution. When the inwardly directed gradient of sodium was replaced by an inwardly directed gradient of choline, potassium, or cesium, the uptake of L-histidine was markedly reduced. Lithium, by contrast, gave results similar to sodium. The ability of lithium ion to substitute for sodium is a characteristic of system $\mathrm{N}$ in rat hepatocytes (11). Compared to no cation, the presence of an inward gradient of choline, potassium, and cesium did cause a modest stimulation in L-histidine uptake. This small stimulation could have been due to the presence of an anion. In fact, L-histidine uptake was reduced slightly $(21 \%)$ by the replacement of chloride with the relatively impermeable anion, sulfate. Substitution of chloride with the more permeable anion, gluconate, had no effect. These results suggest that the uptake of L-histidine is linked primarily to the inward sodium gradient, but there may be a modest anion influence.
Table 1. Effect of various ions on L-histidine uptake in $M M V^{*}$

\begin{tabular}{lc}
\multicolumn{1}{c}{ Salts } & $\begin{array}{c}\text { L-histidine uptake } \\
(\% \text { of } \mathrm{NaCl})\end{array}$ \\
\hline $\mathrm{None}$ & $13.7 \pm 6.3 \dagger$ \\
$\mathrm{NaCl}$ & 100 \\
$\mathrm{KCl}$ & $34.9 \pm 3.4 \dagger$ \\
$\mathrm{Choline} \mathrm{Cl}$ & $47.4 \pm 16.0 \dagger$ \\
$\mathrm{LiCl}$ & $90.0 \pm 3.0$ \\
$\mathrm{CsCl}$ & $34.6 \pm 11.8 \dagger$ \\
$\mathrm{Na}_{2} \mathrm{SO}_{4}$ & $79.0 \pm 18.0$ \\
$\mathrm{Na}^{\text {gluconate }}$ & $105.2 \pm 18.3$ \\
\hline
\end{tabular}

* All salts were included only in the uptake medium at a concentration of $100 \mathrm{mM}$. Results are mean $\pm \mathrm{SD}$ of nine determinations from threevesicle preparations. The actual uptake of $L$-histidine in the presence of $\mathrm{NaCl}$ was $378.5 \pm 63.5 \mathrm{pmol} \cdot \mathrm{mg}$ protein ${ }^{-1} \cdot 30 \mathrm{~s}^{-1}$.

$\dagger p<0.01$ (ANOVA) relative to uptake in the presence of sodium chloride.

To further examine any specificity for the chloride anion, the effect of a chloride gradient on L-histidine uptake was determined using vesicles preloaded with either sodium gluconate or sodium sulfate. Under these conditions, there was no inward sodium gradient. Uptake of histidine was not stimulated by an inward chloride gradient. These results support the above conclusion that the inward sodium-gradient is the principal drive for $\mathrm{L}-$ histidine into the vesicle.

In all studies testing for sodium-dependent uptake, 30-s uptake values with choline chloride (substituted for sodium chloride) were subtracted from uptake with sodium chloride, yielding the 


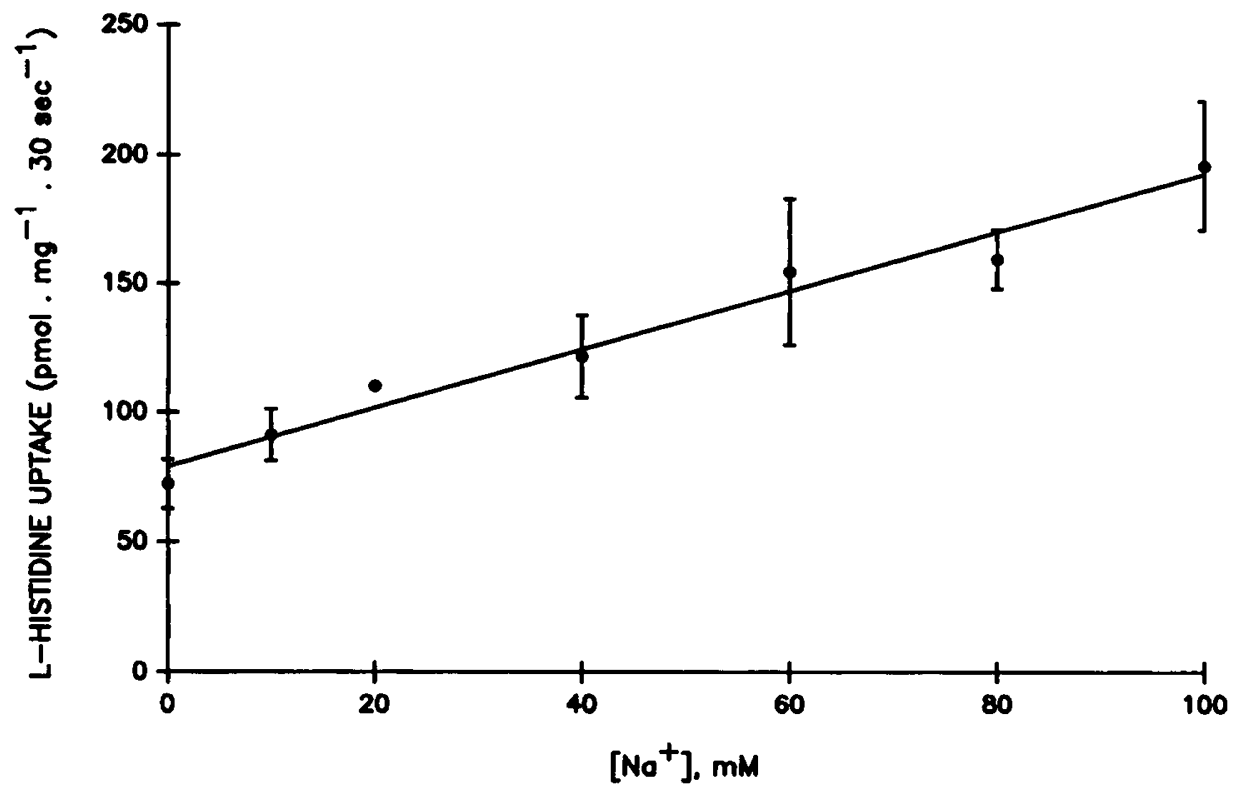

Fig. 3. Dependence of L-histidine uptake on the sodium concentration of the uptake medium. The concentration of $\mathrm{L}$-histidine was $0.1 \mathrm{mM}$.

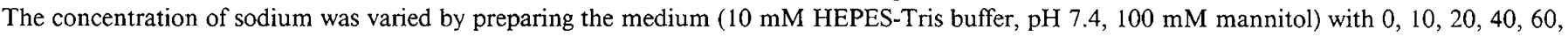
80 , and $100 \mathrm{mM} \mathrm{NaCl}$. The concentration of choline chloride was varied so that the final salt concentration was always $100 \mathrm{mM}$.

sodium-dependent component. Accordingly, when the concentration of sodium in the uptake medium was varied from $0-100$ $\mathrm{mM}$ (differences in ion concentration were made up by choline to a final cation concentration of $100 \mathrm{mM}$ ), L-histidine transport into the intravesicular space increased linearly (Fig. 3).

If L-histidine entry into the vesicle is coupled to sodium transport, factors which alter transmembrane movement of sodium should affect the rate of L-histidine uptake. Therefore, a negative intravesicular electrical potential was established with an outwardly directed potassium gluconate gradient in the presence of the potassium ionophore, valinomycin. Control uptake was determined in the presence of equimolar potassium gluconate on both sides of the membrane. Relative to control conditions, the presence of a negative intravesicle electrical potential stimulated both the initial rate and peak of the histidine uptake (uptake with outward potassium gradient $=181.3 \pm 9.7$; control $=123.2 \pm 16.3 \mathrm{pmol} \cdot \mathrm{mg}^{-1} \cdot 30 \mathrm{~s}^{-1}$ ).

Effect of $\mathrm{N}$-ethylmaleimide on amino acid transport. A criterion for distinguishing amino acid transport system A from other systems is differential sensitivity to $N$-ethylmaleimide (11). Certain transport function may depend, in part, upon functional thiol groups in the membrane carrier proteins. Thiol-reactive reagents, such as $\mathrm{N}$-ethylmaleimide, will inhibit D-glucose transport (21) and selected amino acid transport $(11,22)$. Kilberg et al. (11) showed that $N$-ethylmaleimide inhibits rat hepatocyte system $A$ by $76 \%$ but system $N$ by only $26 \%$. In our study, MeAIB uptake (system A) was inhibited by approximately $30 \%$, whereas the uptake of L-histidine (system $\mathrm{N}$ ), as well as L-cysteine (system ASC), and L-phenylalanine (system L), were not affected (Table 2). Therefore, in human placental MMV, as in rat hepatocytes, the mechanism for L-histidine transport appears to be independent of thiol group inhibition.

Effect of $\mathrm{pH}$ on amino acid uptake. In differentiating various amino acid transport systems, the sensitivity of each system to changes in $\mathrm{H}^{+}$in the medium has been found to be valuable (11, 23, 24). Therefore, we examined the uptake of MeAIB, L-cysteine, L-histidine, and L-phenylalanine at various $\mathrm{H}^{+}$(Fig. 4). The uptake of L-phenylalanine was not affected by changes in medium $\mathrm{pH}$. Both MeAIB and L-histidine uptake were inhibited at either $\mathrm{pH}$ extremes. L-cysteine uptake was stimulated by
Table 2. Sensitivity of amino acid transport systems to inhibition by $N$-ethylmaleimide*

\begin{tabular}{ccccc}
\hline \multirow{2}{*}{$\begin{array}{c}\text { Transport } \\
\text { system }\end{array}$} & \multicolumn{3}{c}{ Uptake (pmol.mg protein ${ }^{-1} \cdot 30 \mathrm{~s}^{-1}$ ) } & \\
\cline { 2 - 4 } & Amino acid & Control & $N$-ethylmaleimide & \% of control \\
\hline A & MeAIB & $144.9 \pm 11.4$ & $99.5 \pm 5.9$ & $68.7 \dagger$ \\
ASC & L-cysteine & $170.4 \pm 21.5$ & $161.4 \pm 10.3$ & 94.7 \\
L & L-phenyl- & $68.4 \pm 1.0$ & $63.2 \pm 9.2$ & 92.4 \\
& alanine & & & \\
N & L-histidine & $165.5 \pm 14.1$ & $162.4 \pm 6.2$ & 105.1 \\
\hline
\end{tabular}

* MMV were incubated for $60 \mathrm{~min}$ at $22^{\circ} \mathrm{C}$ in the presence or absence of $5 \mathrm{mM} \mathrm{N}$-ethylmaleimide (7). The 30 -min uptake assays were performed at $22^{\circ} \mathrm{C}$. For L-cysteine uptake, $5 \mathrm{mM}$ dithiothreitol was included in the incubation. The results are mean \pm SD from six determinations. The rate for MeAIB, L-cysteine, and L-histidine are $\mathrm{Na}^{+}$-dependent rates; for L-phenylalanine, the uptake rate was observed in choline-containing medium. L-phenylalanine uptake in $\mathrm{Na}^{+}$-containing medium was not different from that in choline-containing medium.

$\dagger p<0.01$ (paired $t$-test) relative to control.

increasing $\mathrm{H}^{+}$in the extravesicular medium such that it was highest at $\mathrm{pH} 6$ and lowest at $\mathrm{pH} 8.5$. The correlation between L-cysteine uptake and $\mathrm{H}^{+}$, is thought to result from activation of the carrier molecule by protonation (25). The $\mathrm{pH}$ sensitivity pattern for L-histidine uptake distinguishes it from L-cysteine uptake, and hence, system ASC $(23,24)$.

Inhibition of L-histidine by other sodium-dependent amino acids. To study the effects of different amino acids upon Lhistidine uptake, each potential inhibiting substrate was added at $1 \mathrm{mM}$. This is 10 -fold greater than the $\mathrm{L}$-histidine concentration. As shown in Table 3, L-histidine uptake was not inhibited by MeAIB, transport of which is thought to be specific for system A. $\alpha$-amino isobutyric acid, whose transport seems to overlap with many transport systems, has a modest inhibitory effect on L-histidine uptake. The results are similar to that reported in rat hepatocytes and further suggest an independent transport system for L-histidine. As expected, the greatest inhibition of L-histidine uptake occurred with L-histidine itself or L-glutamine, another amino acid with a nitrogen-containing side chain. 


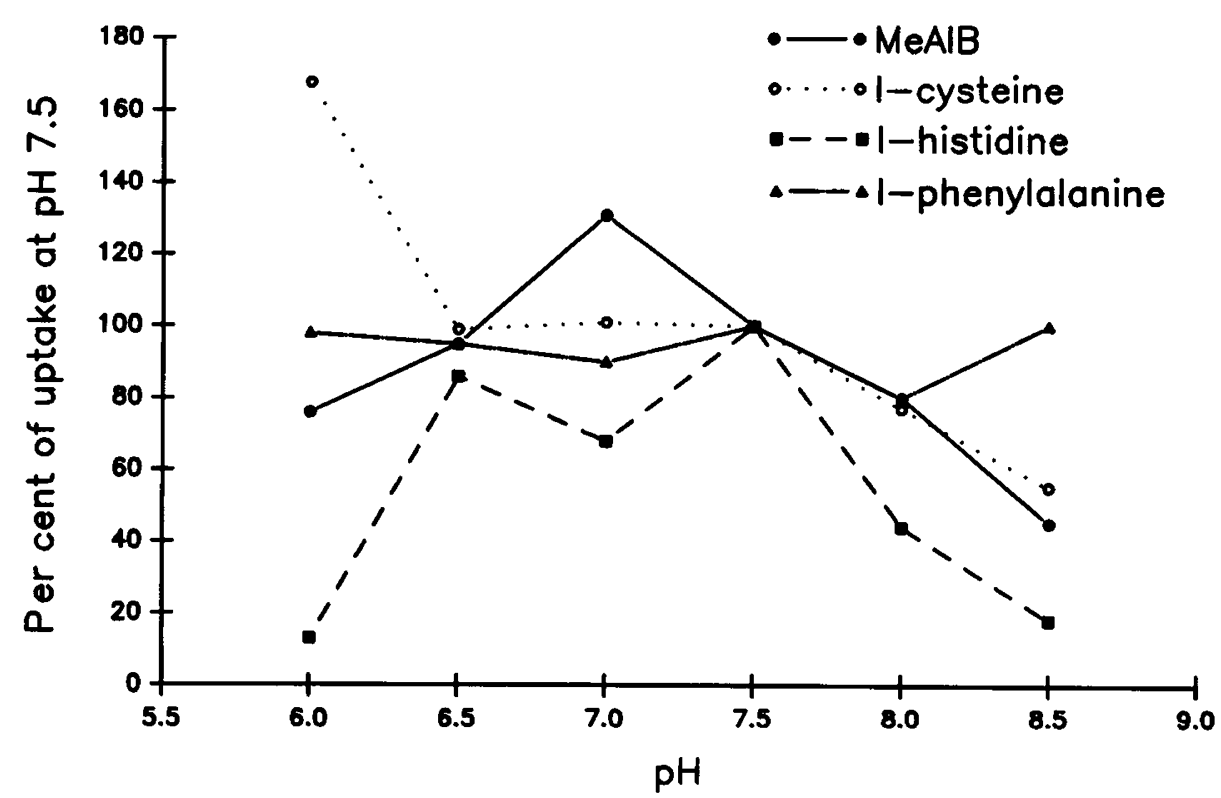

Fig. 4. The relationship between $\mathrm{pH}$ and the uptake of MeAIB, L-cysteine, L-histidine, and L-phenylalanine. Uptake of amino acids by the human placental MMV were determined at varying $\mathrm{pH}$ values between 6 and 8.5. The MMV preparation was added to the incubation medium (1:9; vol/ $\mathrm{vol}$ ) at $22^{\circ} \mathrm{C}$ for $30 \mathrm{~s}$. Uptake of L-cysteine was carried out in the presence of $5 \mathrm{mM}$ dithiothreitol. The data are averages of three determinations. The data presented for MeAIB, L-cysteine and L-histidine are rates for the sodium-dependent component only, with the rate in choline subtracted from the rate determined in sodium. There were no differences between the rate of uptake for L-phenylalanine in sodium or choline at any $\mathrm{pH}$ value. The uptake rate value at $\mathrm{pH} 7.5$ for each amino acid are: MeAlB $=127.7 \pm 13.9 ; \mathrm{L}$-cysteine $=71.8 \pm 3.9 ; \mathrm{L}$-histidine $=103.7 \pm 6.0$; and Lphenylalanine $=115.8 \pm 21.8 \mathrm{pmol} \cdot \mathrm{mg}$ protein ${ }^{-1} \cdot 30 \mathrm{~s}^{-1} .{ }^{*} \mathrm{p}<0.01$ relative to uptake at $\mathrm{pH} 7.5$ (ANOVA).

Table 3. Inhibition of $\mathrm{Na}^{+}$-dependent L-histidine uptake by various $\mathrm{Na}^{+}$-dependent amino acids*

\begin{tabular}{cc}
\hline Amino acid, $1 \mathrm{mM}$ & \% of control $\dagger$ \\
\hline None & 100 \\
AIB & $72.6 \ddagger$ \\
MeAIB & 101.4 \\
L-cysteine & 100.0 \\
L-glutamine & $39.0 \ddagger$ \\
L-histidine & $34.2 \ddagger$ \\
\hline
\end{tabular}

* Uptake of $0.1 \mathrm{mM}$ L-histidine by MMV were measured in the presence or absence of $1 \mathrm{mM}$ inhibitor. The uptake was for $30 \mathrm{~s}$ at $22^{\circ} \mathrm{C}$ Uptake was determined in the presence or absence of $\mathrm{Na}$ or choline. When L-cysteine was tested, $5 \mathrm{mM}$ dithiothreitol was included in the medium. The data are for $\mathrm{Na}^{+}$-dependent fraction after subtracting uptake in choline. Results are averages from three-nine determinations.

$\dagger$ Actual L-histidine uptake in the absence of inhibiting amino acid was $281.5 \pm 33.3 \mathrm{pmol} \cdot \mathrm{mg}$ protein ${ }^{-1} \cdot 30 \mathrm{~s}^{-1}$.

$\ddagger p<0.01$ relative to control uptake in the absence of inhibiting amino acid (ANOVA).

Inhibition of MeAIB and L-cysteine uptake by L-histidine. The above results demonstrate that high concentrations of MeAIB and L-cysteine probably do not influence transport of L-histidine via its transport system. Alternatively, a high concentration of $L-$ histidine was tested against model amino acids for either system A or ASC, namely MeAIB or L-cysteine.

A Dixon plot of the results indicate that the uptake of MeAIB was inhibited by L-histidine but clearly not in a competitive manner. The plot appears to show noncompetitive inhibition (Fig. 5). Similarly, the uptake of L-cysteine (Fig. 6) and serine (data not shown) were noncompetitively inhibited by L-histidine.

As L-histidine does not competitively inhibit MeAIB or Lcysteine uptake, it is unlikely that L-histidine is transported by either the A or ASC system. The results confirm experiments with $N$-ethylmaleimide and $\mathrm{pH}$, indicating that uptake of Lhistidine occurs by a distinct transport mechanism. However, noncompetitive inhibition by L-histidine implies that there may be indirect interaction with the A and ASC transport systems, altering affinity or activity.

Inhibition of L-histidine uptake by L-glutamine. To demonstrate that the placental system of L-histidine transport is shared by other amino acids which have nitrogen-containing side chains, the effect of varying concentrations of L-glutamine was studied. As shown by the Dixon plot in figure $7, \mathrm{~L}$-histidine uptake was competitively inhibited by L-glutamine. Coupled with the simple (one concentration) inhibition of L-histidine uptake by L-glutamine, shown in Table 3, these data provide evidence for the presence of a distinct carrier system for amino acids with a nitrogen-containing side chain.

To further demonstrate that L-histidine and L-glutamine occupy the same transport site, transstimulation of ${ }^{3} \mathrm{H}$-histidine uptake was assessed. Vesicles which were preloaded with either L-histidine or L-glutamine $(100 \mu \mathrm{M})$ were used to measure sodium-stimulated L-histidine uptake. Preloading with L-histidine and L-glutamine increased L-histidine uptake by $184 \pm 6$ and $213 \pm 5 \%$, respectively.

In summary, uptake of L-histidine by human placental MMV demonstrates characteristics similar to those described for system $\mathrm{N}$ in rat hepatocytes. Uptake is sodium dependent and stimulated by an electrical potential, but not inhibited by a model amino acid of the A system. There is a distinct pattern of $\mathrm{pH}$ sensitivity, and $N$-ethylmaleimide has no inhibitory effect. Finally, transport is competitively shared with L-glutamine, which also has a nitrogen-containing side chain.

The findings are the first demonstration of the putative system $\mathrm{N}$ in human tissue and may be added to the other amino acid transport systems described for the placenta $(8,26)$. The human placenta is a readily available source of transport epithelium and may be a useful experimental resource for studies of human epithelial transport biology. 


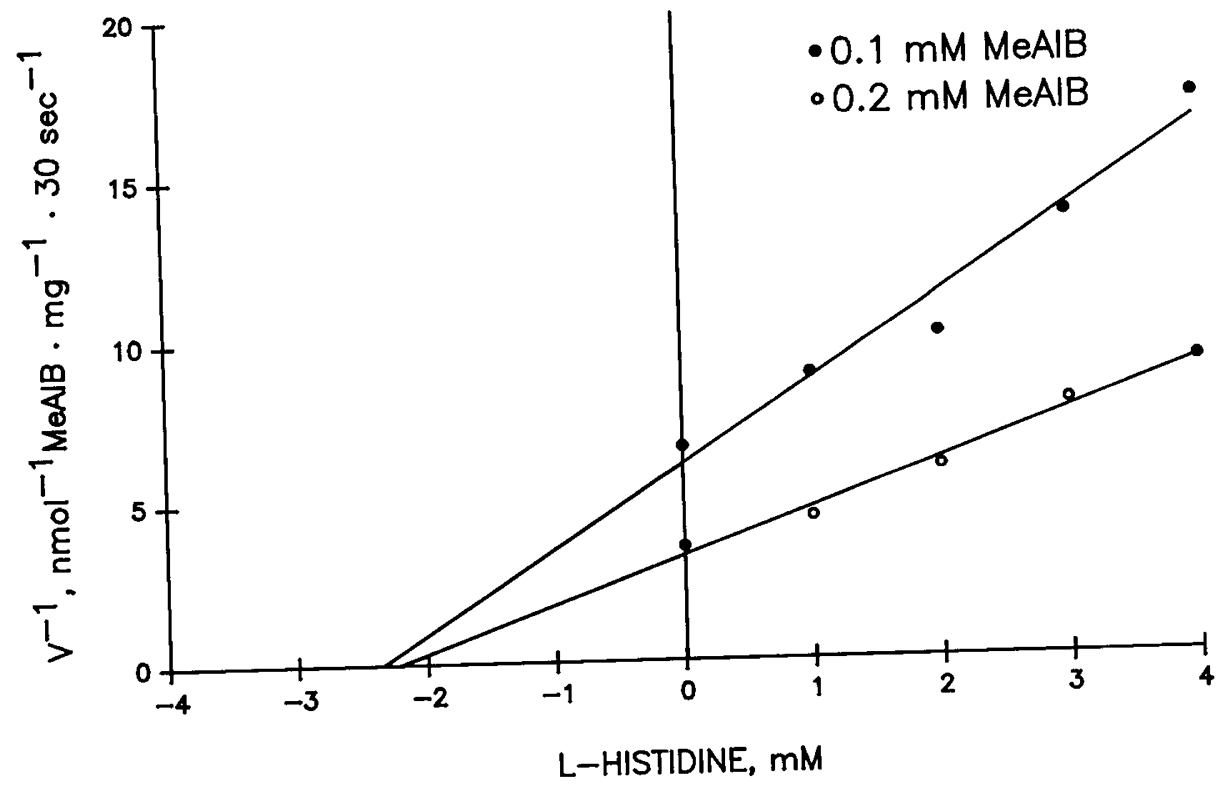

Fig. 5. Dixon plot of MeAIB uptake inhibition by L-histidine. The 30-s uptake of MeAIB at 0.1 and $0.2 \mathrm{mM}$ was determined in the presence of $0,1,2,3$, and $4 \mathrm{mM}$ L-histidine. The results represent the sodium-dependent component of MeAIB uptake only.

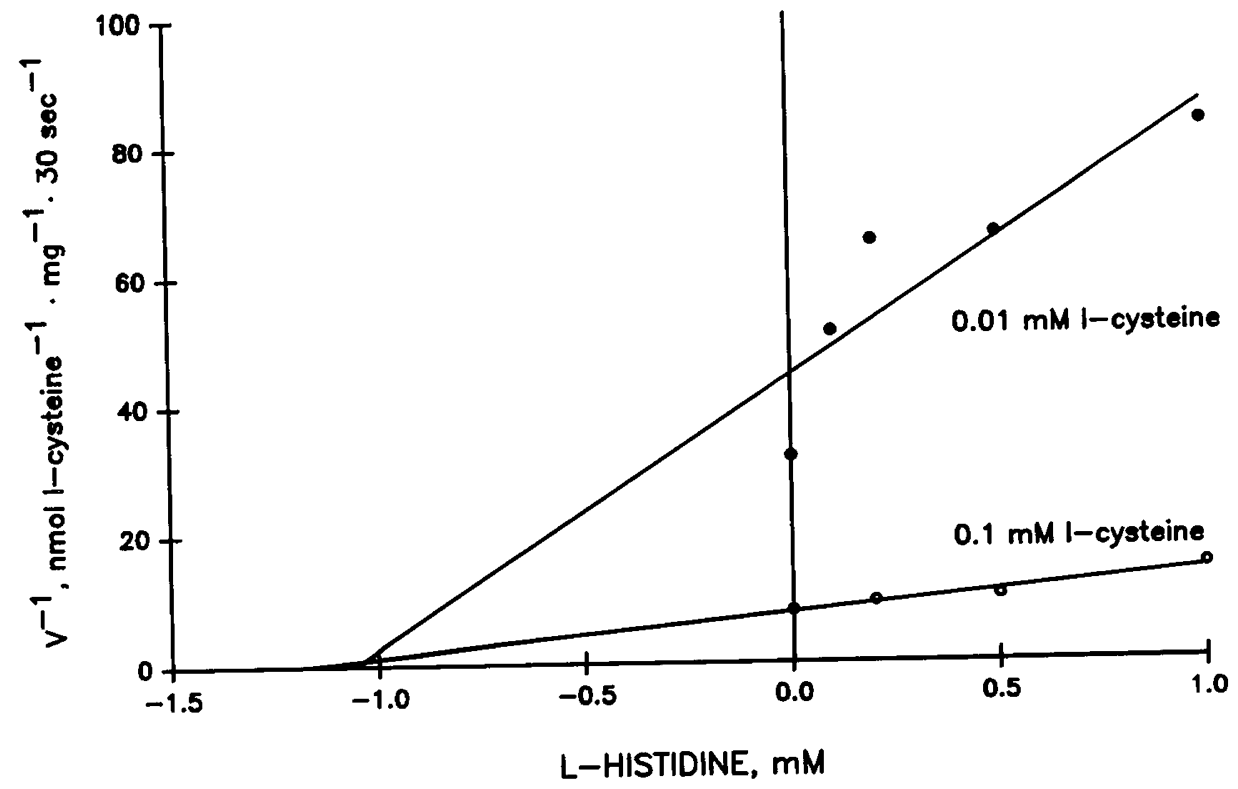

Fig. 6. Dixon plot of L-hicysteine uptake inhibition by L-histidine. The uptake assay was performed as described in the legend of Figure 7, except with $0,0.1,0.2,0.5$, and $1.0 \mathrm{mM}$ L-histidine, and $5 \mathrm{mM}$ dithiothreitol was included in the medium. 


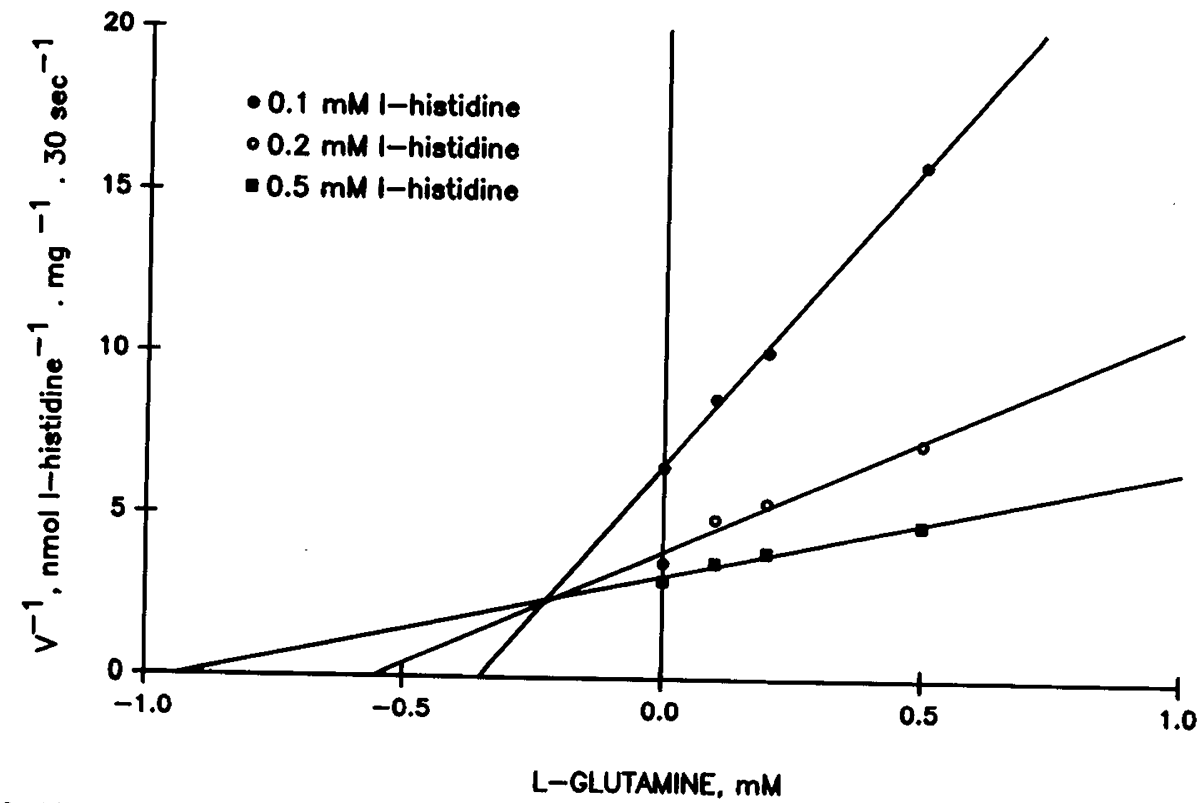

Fig. 7. Dixon plot of L-histidine uptake inhibition by L-glutamine. The uptake assay was performed as described in the legend of Figure 5 except that $0.1,0.2$, and $0.5 \mathrm{mM}^{3} \mathrm{H}$-L-histidine and $0,0.1,0.2,0.5$, and $1.0 \mathrm{mM}$ L-glutamine were used.

Acknowledgments. The authors thank Ms. Susan Stross and her staff in the North Shore University Hospital labor and delivery ward for their assistance; Miss Lourdes Porres and $\mathrm{Mr}$. Richard T. Kershen for technical assistance.

\section{REFERENCES}

1. Yudilevich DL, Sweiry JH 1985 Transport of amino acids in the placenta. Biochim Biophys Acta 822:169-201

2. Smith NC, Brush MG, Luckett S 1974 Preparation of human placental villous surface membrane. Nature 252:302-303

3. Ruzycki SM, Kelley LK, Smith CH 1978 Placental amino acid uptake. IV. Transport by microvillous membrane vesicles. Am J Physiol 234:C27-C35

4. Boyd CAR, Lund EK 1981 L-Proline transport by brush border membrane vesicles prepared from human placenta. J Physiol 315:9-19

5. Montgomery D, Young D 1982 The uptake of naturally occurring amino acids by plasma membrane of the human placenta. Placenta 3:13-20

6. Asai M, Keino H, Kashiwamata S 1982 L-Alanine uptake by microvillous brush border membrane vesicles prepared from human placenta. Biochem Int 4:377-384

7. Ganapathy ME, Leibach FH, Mahesh VB, Howard JC, Devoe ID, Ganapathy V 1986 Characterization of tryptophan transport in human placental brushborder membrane vesicles. Biochem J 238:201-208

8. Kudo Y, Yamada K, Fujiwara A, Kawasaki T 1987 Characterization of amino acid transport systems in human placental brush-border membrane vesicles. Biochim Biophys Acta 904:309-318

9. White A, Handler P, Smith EL 1973 Principles of Biochemistry, 5th ed McGraw-Hill, New York pp 629-655

10. Scriver CR, Rosenberg LE 1973 Amino Acid Metabolism and Its Disorders. WB Saunders Co, Philadelphia, pp 370-377

11. Kilberg MS, Handlogten ME, Christensen HN 1980 Characteristics of an amino acid transport system in rat liver for glutamine, asparagine, histidine and closely related analogs. J Biol Chem 255:4011-4019

12. Balkovetz DF, Leibach FH, Mahesh VB, Devoe LD, Cragoe EJ, Ganapathy V
1986 Am J Physiol 251:C852-C860

13. Chen PS, Toribara TY, Warner H 1956 Microdetermination of phosphorus, Anal Chem 28:1756-1758

14. Marks MJ, Seeds NW 1978 A heterogeneous ouabain-ATPase interaction in mouse brain. Life Sci 23:2735-2744

15. Whitsett JA, Wallick ET $1980\left[{ }^{3} \mathrm{H}\right]$ Ouabain binding and $\mathrm{Na}^{+}-\mathrm{K}^{+}-\mathrm{ATP}$ ase activity in human placenta. Am J Physiol 238:E38-E45

16. Markwell MA, Haas SM, Bieber LL, Tolbert NE 1978 A modification of the Lowry procedure to simplify protein determination in membrane and lipoprotein samples. Anal Biochem 87:206-210

17. Lowry OH, Rosebrough NJ, Farr AL, Randall RJ 1951 Protein measurement with Folin phenol reagent. J Biol Chem 193:265-275

18. Brunette MG, Allard S 1985 Phosphate uptake by syncytial brush border membranes of human placenta. Pediatr Res 19:1179-1182

19. Kletzien RF, Pariza MW, Becker JE, Potter VR 1975 A method using 3-Omethyl-D-glucose and phloretin for the determination of intracellular water space of cells in monolayer culture. Anal Biochem 68:537-544

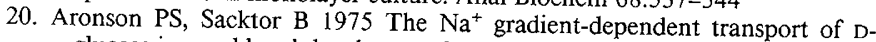
glucose in renal brush border membranes. J Biol Chem 250:6032-6039

21. Poiree JC, Mangual R, Sudaka P 1979 Identification of a protein componen of the horse-kidney brush border D-glucose transport system. Biochem Biophys Res Commun 90:1387-1392

22. Hayes MR, McGivan JD 1983 Comparison of the effects of certain thiol reagents on alanine transport in plasma membrane vesicles from rat liver and their use in identifying the alanine carrier. Biochem J 214:489-495

23. Oxender DL, Christensen HN 1963 Distinct mediating systems for the transport of neutral amino acids by the Erlich cell. J Biol Chem 238:3686-3699

24. Christensen HN 1975 Biological Transport, 2nd ed. W. A. Benjamin, Inc. Reading, MA

25. Makowske M, Christensen HN 1982 Hepatic transport system interconverted by protonation from service for neutral to service for anionic amino acids. J Biol Chem 257:14635-14638

26. Miller RK, Berndt WO 1975 Mechanisms of transport across the placenta: an in vitro approach. Life Sci 15:7-30 